\title{
The past, the present and the future of nanotechnologies
}

\author{
János B. NAGY \\ University of Namur, Belgium, janos.bnagy1@gmail.com
}

\begin{abstract}
Artists from the time of Mesopotamia or Egypt and in the Middle Ages astonished us with various coloured Stained-glass windows, prepared with the help of metal nanoparticles.

The paper will deal with zeolites, nanoparticles and carbon nanotubes. The latter will be developed more extensively, because we have founded the Nanocyl company, selling carbon nanotubes and it has become the best European company. One carbon nanotube is 100,000 times thinner than a human hair, it is very light - twice as light as aluminium -, its mechanical resistance is much higher than that of steel and it conducts electricity better than metal conductors. The use of carbon nanotubes is very important in nanotechnology. For example, with the help of coiled carbon nanotubes, the weight of a single nanoparticle can be measured, it is equal to one femtogram ( $10^{-15}$ gram). Carbon nanotubes are used in car spray painting to cancel the build-up of static electricity. With the help of carbon nanotubes, it is possible to decrease the velocity of flame propagation, when they are included in composite materials. Carbon nanotubes are also very good as sensors for toxic gases. Their uses will take up the most part of this paper.

The future of nanotechnology will be illustrated by nanomachines, by the lift between the Earth and the Moon, and by graphene (one single sheet of graphite). The use of carbon nanotubes will be evoked in waste water cleaning, in the production of drinking water from seawater.
\end{abstract}

Keywords: nanoparticles, carbon nanotubes, coiled carbon nanotubes, nanotechnology.

\section{Results and discussion}

Nanoparticles have two essential properties: the very high surface area and the physical properties that depend on the size of the particles.

Figure 1. illustrates the importance of the surface area. Let us start with a cube of $1 \mathrm{~m}$ edge. This gives a surface area of $6 \mathrm{~m}^{2}$. If we divide the edge by 1,000 , we get a cube of $1 \mathrm{~mm}^{3}$ with a surface of $6 \mathrm{~m}^{2}$. As we can form 1,000,000,000 cubes from the initial one - the total volume being kept constant - the total surface becomes equal to $\left(6 \times 10^{9}\right) \mathrm{m}^{2}$ or $6,000 \mathrm{~m}^{2}$.

If we continue to divide by $1,000,000,000$ we arrive at cubes each of $1 \mathrm{~nm}$ edge. The total the surface area becomes in this case $6,000,000,000$ $\left(6 \times 10^{9}\right) \mathrm{m}^{2}$.

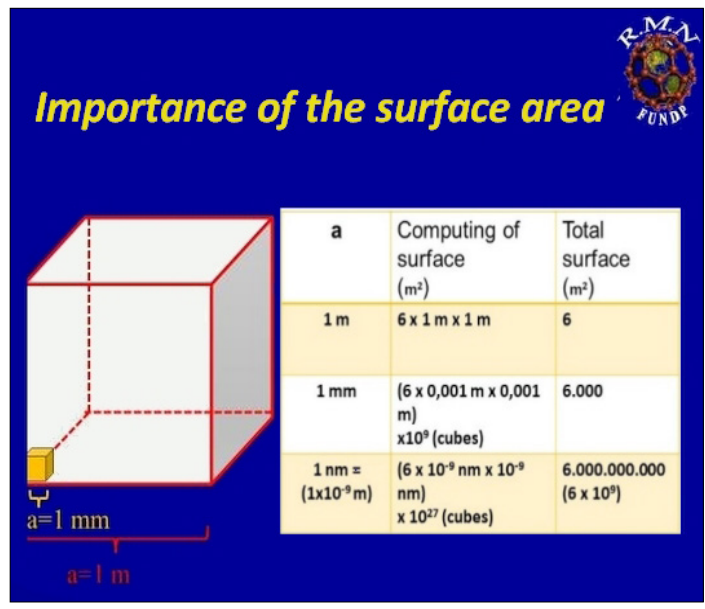

Figure 1. The importance of the surface area. 
As a consequence, the total surface increases always by the same amount as the number used to divide the initial edge.

The change of the physical properties is illustrated in Figure 2.

This shows the change of colour of the fullerenes - which are balls formed only by carbon atoms as a function of their size [1].

The zeolites are aluminium silicates either in natural or in synthesized form [2]. They are composed of cavities and channels of nanoscopic size (Figure 3.). They are used as adsorbents, as ionic exchanger due to the presence of cations neutralizing the negative charges linked to aluminium and as catalyst. Those who drive a car can be sure that their gasoline has seen zeolites in their life as they are used to cut the long chains of the molecules composing the crude petroleum.

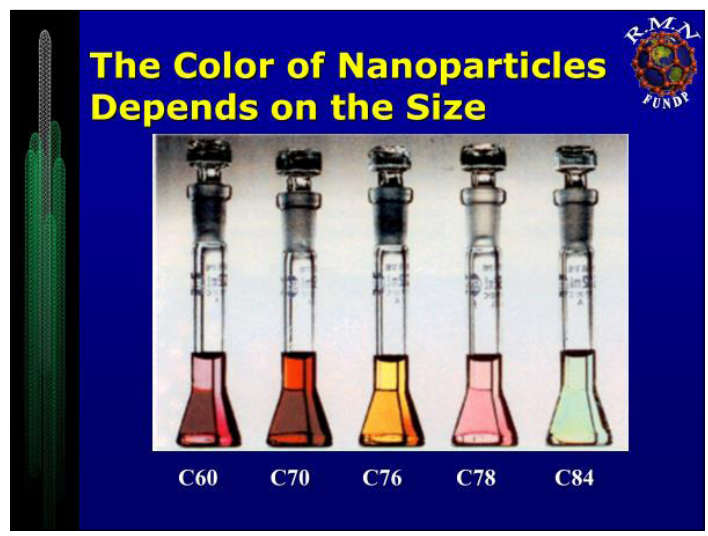

Figure 2. The colour of nanoparticles depends on their size.

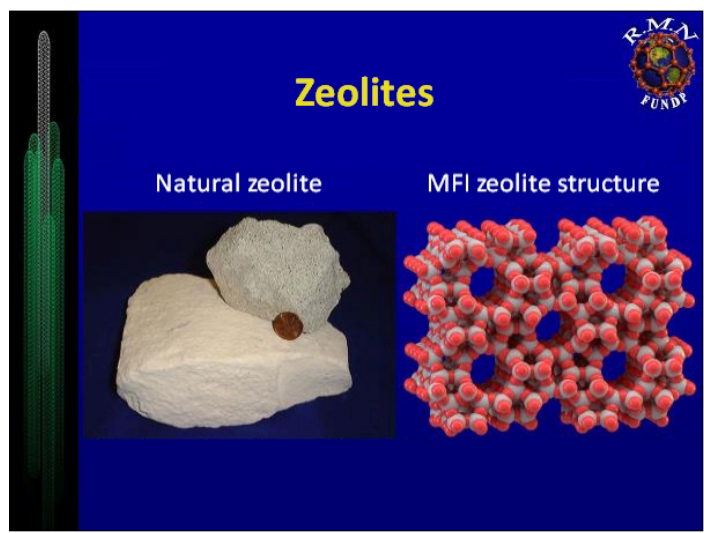

Figure 3. Natural and synthesized zeolites.
Inorganic nanoparticles can be prepared by reducing the cations dissolved in microemulsions formed by three components, water, surfactant and organic solvent [3]. The water dispersed in the organic solvent - thanks to the surfactant forms nanocages where the reaction of reduction occurs and the so-formed nano-particles are stabilized by the surfactant.

Figure 4. represents the formation of $\mathrm{AgBr}$ nanoparticles in two different conditions. In the first case a kinetic control takes place and the colliding nanoparticles form a fractal structure (in black in the figure). In the second case, thermodynamic control occurs and the nanoparticles tend to form a more stable structure, i.e. a sphere. The reaction has not completely finished and as an intermediate state a heart-like structure is formed (in red in the figure). This figure could finally be red as „I love nano-particles”.

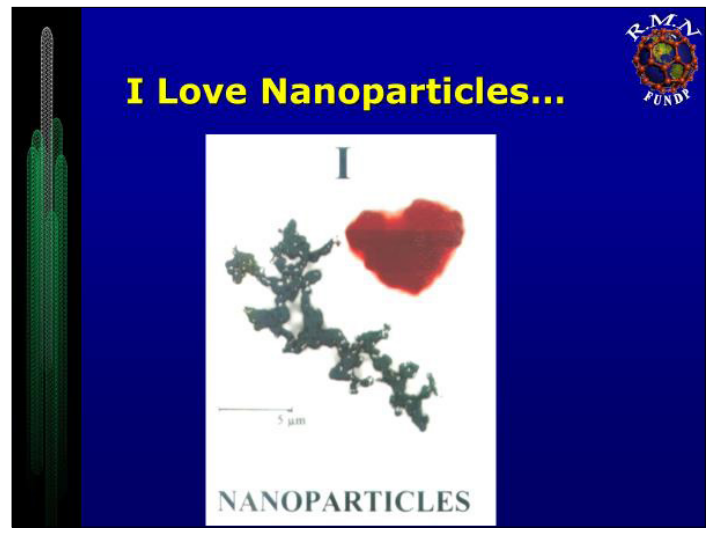

Figure 4. AgBr nanoparticles forming a fractal structure (in black) and controlled by thermodynamic stability tending to a spherical form (in red).

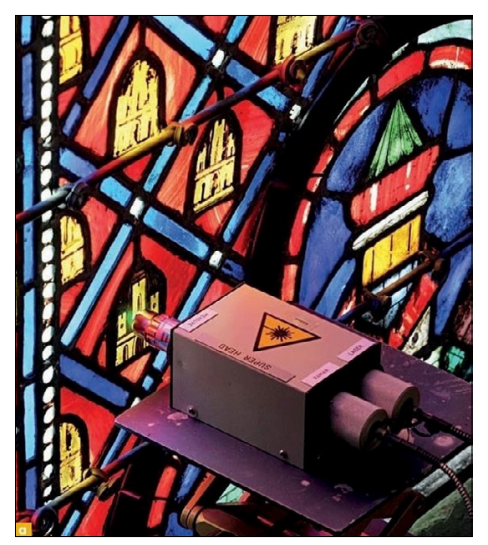

Figure 5. Stained - glass windows of the Middle Age (Sainte Chapelle, Paris, XII. Century). 


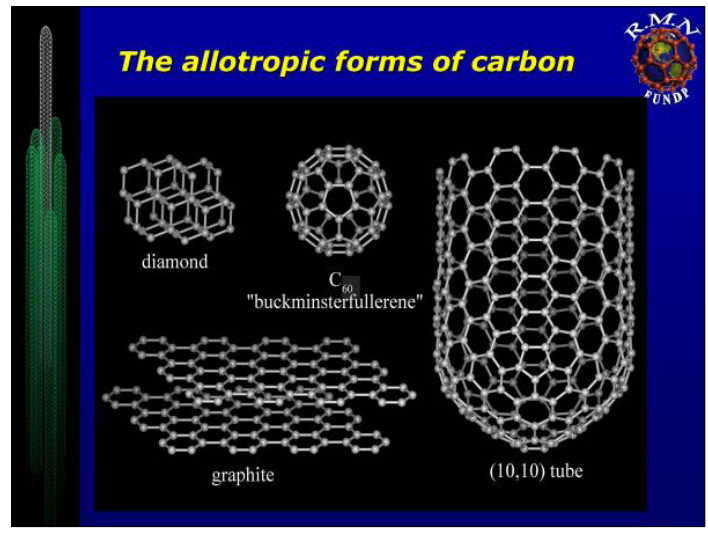

Figure 6. The allotropic forms of carbon.

\section{Fullerenes Family $C_{n}$}

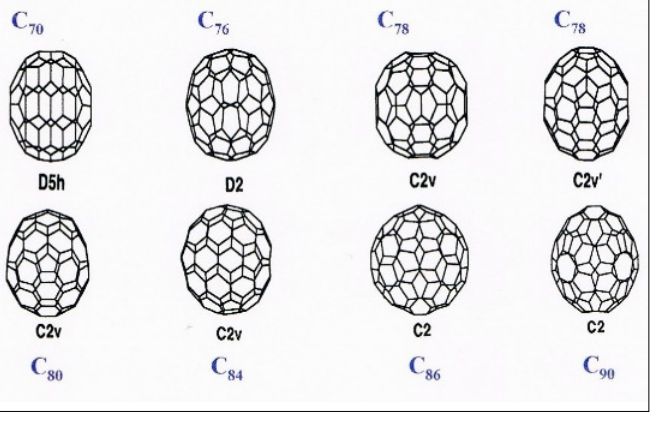

Figure 7. Fullerenes family.

As the past of nanotechnology, we show a beautiful picture composed of nano-particles of silver (giving the yellow colour) and of copper (giving the red colour) leading to the stained - glass windows in the Middle Age (Figure 5.).

This is proof that nanotechnology was discovered prior to the twentieth century.

Figure 6. shows the various allotropic forms of carbon.

Diamond is formed by a tetrahedral structure linking every carbon atom. It has a beautiful colour and is one of the hardest materials. When all the carbon atoms are linked to three other neighbours, a plane structure is obtained formed by six - membered rings. This is graphite, and it is quite breakable, because the planes can slip over each other. We know this from the way a pencil usually breaks easily. Fullerenes are balls formed only from carbon atoms and the carbon nano - tubes were initially considered as elongated fullerenes.

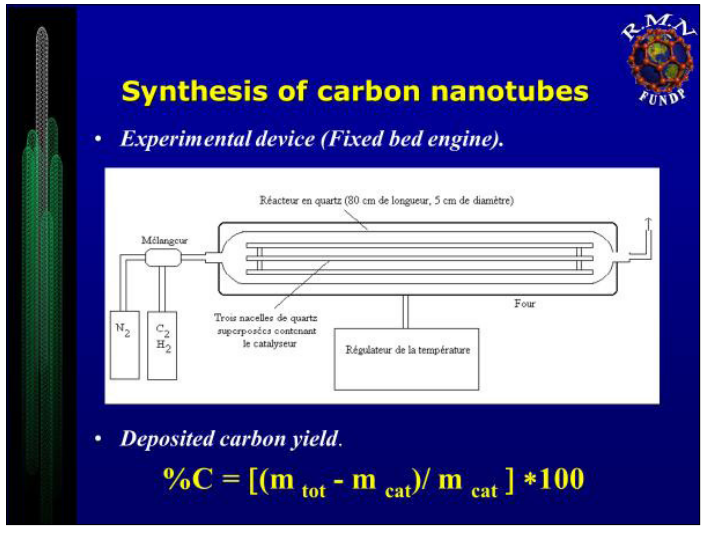

Figure 8. Synthesis of carbon nanotubes by Chemical Vapour Deposition.

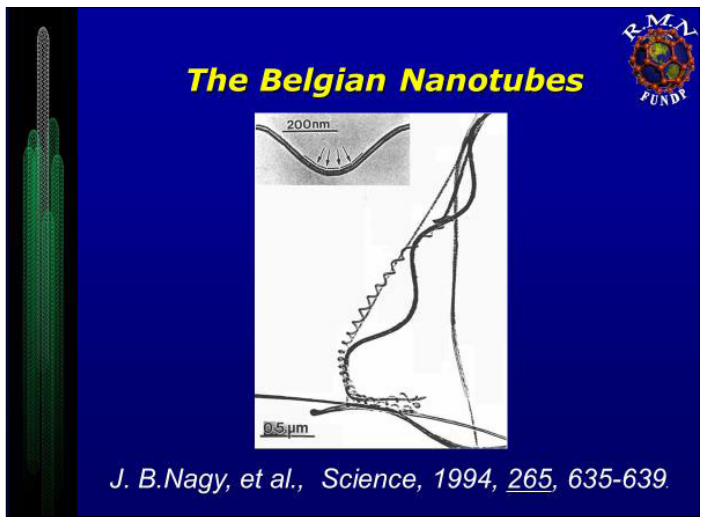

Figure 9. The Belgian nanotubes: Nanoharp.

Figure 7. Illustrates some members of the fullerenes family [4].

Bob Curl, Harry Kroto and Rick Smalley received the Nobel Prize in chemistry in 1996 for the discovery of $\mathrm{C}_{60}$ fullerenes.

The main part of the paper will be occupied by the synthesis and use of carbon nanotubes.

We used a very simple method to prepare carbon nanotubes. A hydrocarbon, for example acetylene, is decomposed on supported metal nanoparticles at high temperature, i.e. $700{ }^{\circ} \mathrm{C}$. The generally used metal particles are $\mathrm{Fe}$, $\mathrm{Co}$ or $\mathrm{Fe}-$ Co, supported on various solids such as zeolites or silica gel. The method is called Catalytic Vapour Deposition (CVD) (Figure 8.).

Figure 9. shows various multiwalled carbon nanotubes obtained on a Co/silica catalyst. We can see linear nanotubes and coiled nanotubes [5]. The figure could represent a „nanoharp”. 


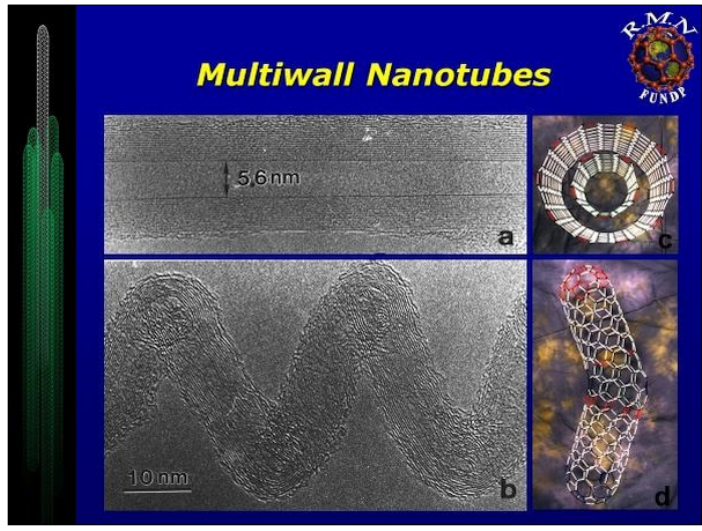

Figure 10. High resolution Transmission Electron Microscope (TEM) pictures of Multi Walled Nanotubes (MWNT) in the linear form and in the coiled form.

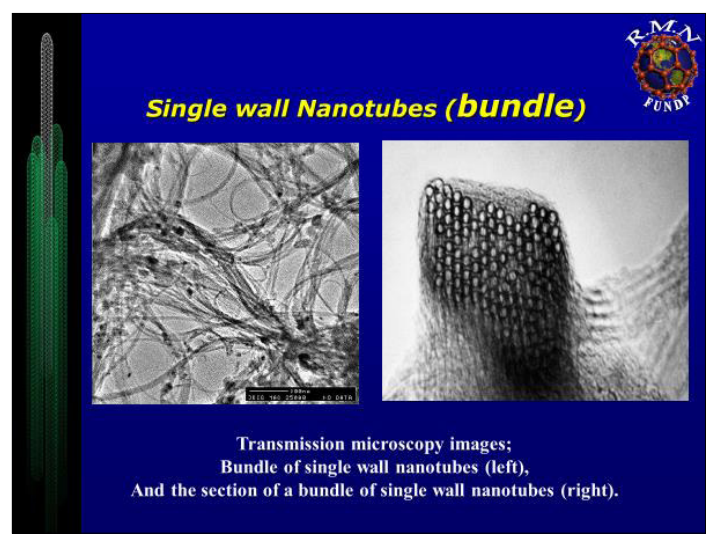

Figure 11. Single Walled Nanotubes (SWNT) forming bundles.

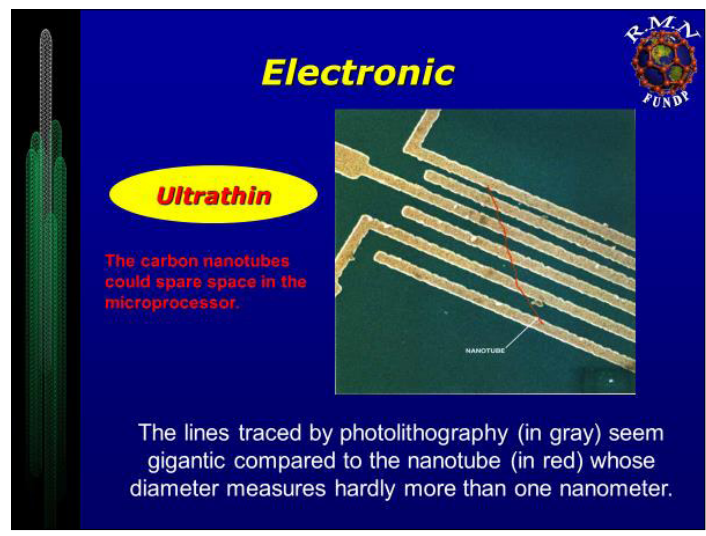

Figure 12. The very thin size of Single Walled Carbon Nanotubes
Table 1. Properties of Single Walled Carbon Nanotubes.

\begin{tabular}{|c|c|c|c|c|}
\hline \multicolumn{2}{|c|}{ Properties } & SWNTs & \multicolumn{2}{|c|}{ For memory } \\
\hline & SIZE & $\begin{array}{l}0.6 \text { to } 1.8 \mathrm{~nm} \text { in } \\
\text { diameter. }\end{array}$ & \multicolumn{2}{|c|}{$\begin{array}{l}\text { The lithography by electron } \\
\text { beam can create broad lines of } \\
50 \mathrm{~nm} \text { and of some } \mathrm{nm} \text { of } \\
\text { thickness. }\end{array}$} \\
\hline & DENSITY & 1.33 to $1.40 \mathrm{~g} / \mathrm{cm}^{3}$. & \multicolumn{2}{|c|}{$\begin{array}{l}\text { Aluminium has a density of } 2.7 \\
\mathrm{~g} / \mathrm{cm}^{3}\end{array}$} \\
\hline & STRENGTH & 45 billion Pascal. & \multicolumn{2}{|c|}{$\begin{array}{l}\text { The strongest steel alloys break } \\
\text { at approximately two billions of } \\
\text { Pascal. }\end{array}$} \\
\hline & ELASTICITY & $\begin{array}{l}\text { They can be } \\
\text { strongly curved } \\
\text { without irreversible } \\
\text { deformation. }\end{array}$ & \multicolumn{2}{|c|}{$\begin{array}{l}\text { Metals and the carbon fibers are } \\
\text { fractured at the limits between } \\
\text { the grains. }\end{array}$} \\
\hline & $\begin{array}{l}\text { CURRENT } \\
\text { TRANSPORT }\end{array}$ & \multicolumn{2}{|c|}{$\begin{array}{l}\text { Estimated at one billion } \\
\mathrm{A} / \mathrm{cm}^{2} \text {. }\end{array}$} & $\begin{array}{l}\text { The copper wire roasts at } \\
\text { approximately one million } \\
\mathrm{A} / \mathrm{cm}^{2} \text {. }\end{array}$ \\
\hline & $\begin{array}{l}\text { FIELD } \\
\text { EMISSION }\end{array}$ & \multicolumn{2}{|c|}{$\begin{array}{l}\text { They can activate } \\
\text { phosphorus with a } \\
\text { tension ranging between } \\
1 \text { and } 3 \\
\text { volts when the electrodes } \\
\text { are distant by } 1 \mu \mathrm{m} \text {. }\end{array}$} & $\begin{array}{l}\text { Molybdenum tip requires } \\
\text { electric fields from } 50 \text { to } 100 \\
\text { volts per } \\
\text { micrometer and have very } \\
\text { limited life time. }\end{array}$ \\
\hline & $\begin{array}{l}\text { HEAT } \\
\text { TRANSFER }\end{array}$ & \multicolumn{2}{|c|}{$\begin{array}{l}\text { It would be } 6000 \mathrm{~W} / \mathrm{m} . \mathrm{K} \\
\text { at ambient temperature. }\end{array}$} & $\begin{array}{l}\text { A quasi pure diamond } \\
\text { transmits } 3320 \mathrm{~W} / \mathrm{m} . \mathrm{K} \text {. }\end{array}$ \\
\hline & $\begin{array}{l}\text { THERMAL } \\
\text { STABILITY }\end{array}$ & $\begin{array}{l}\text { Stable up to } 2800^{\circ} \\
\text { vacuum and to } 450^{\circ} \\
\text { in air. }\end{array}$ & $\mathrm{C}$ in & $\begin{array}{l}\text { The metal wire of micro } \\
\text { chips melts between } 600 \\
\text { and } 1000^{\circ} \mathrm{C} \text {. }\end{array}$ \\
\hline
\end{tabular}

Figure 10. illustrates a high resolution transmission electron microscope picture of a coiled multiwalled carbon nanotube. The tube is formed by some 10 concentric layers. The coiled carbon nanotubes were called "Belgian tubes " by Japanese and South - Korean scientists as we synthesized them for the first time. We have founded the Nanocyl company in order to prepare various carbon nanotubes in large amounts.

Single walled carbon nanotubes can also be prepared and they form bundles, because the van der Waals attraction is very high between the tubes (Figure 11.).

The carbon nanotubes can be used in nanotechnology. They are thinner than the frame obtained by lithography and one can put many more electric conductors in the same volume (Figure 12.).

Table 1. compares the various properties of carbon nanotubes with other known materials. They are thinner than the wire made by silicon to be used in computers.

They are twice as light as the corresponding light metal aluminium used in aeroplane parts. They are more resistant than steel and they conduct electricity better than known metallic conductors. 


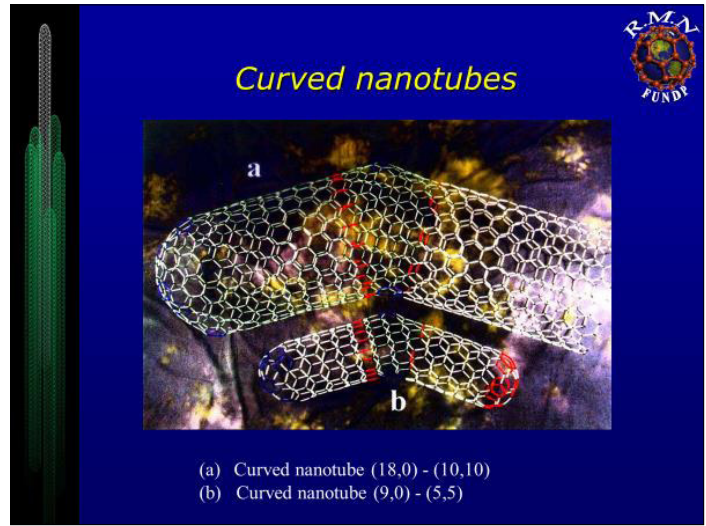

Figure 13. Curved nanotubes.

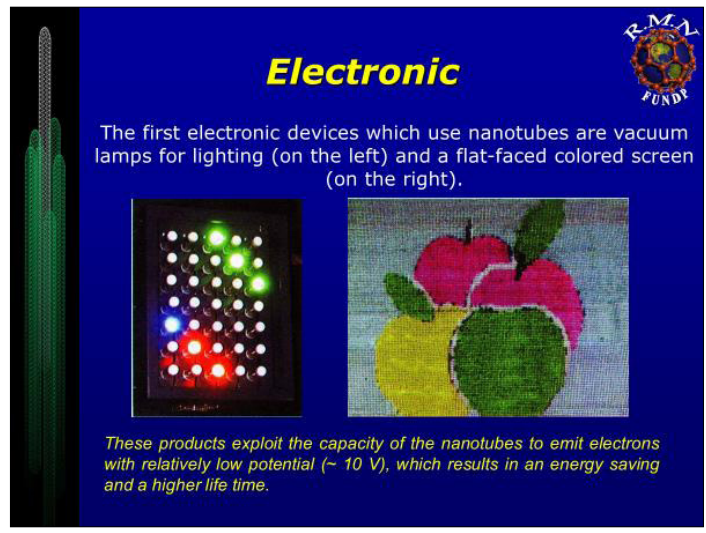

Figure 14. Light emitting properties of carbon nanotubes.

They emit electrons easily and are already used in car painting in order to reduce the static electricity on the surface. They are very flexible, and they come back to the initial position after cancelling the initial force. Their heat transfer is twice as good as the best material known so far. The thermal stability is high in vacuum, stable up to $2,800^{\circ} \mathrm{C}$, but in air it is oxidized at $450{ }^{\circ} \mathrm{C}$. It should be noted that metal microchips melt between $600{ }^{\circ} \mathrm{C}$ and $1,000^{\circ} \mathrm{C}$.

Figure 10. also shows models to illustrate the two concentric layers in a MWNT. Let us concentrate now on the curved nanotubes of Figure 13. We can distinguish clearly two different structures formed by the six - membered rings. When the sides of the six - membered rings are perpendicular to the tube axis, it is a metal conductor, while when the sides of the six - membered rings are parallel with the tube axis, it is a semi - conductor. This curved nanotube can hence be used in nanotechnology, as a switch, letting the current pass in one tube and cutting it in the other.

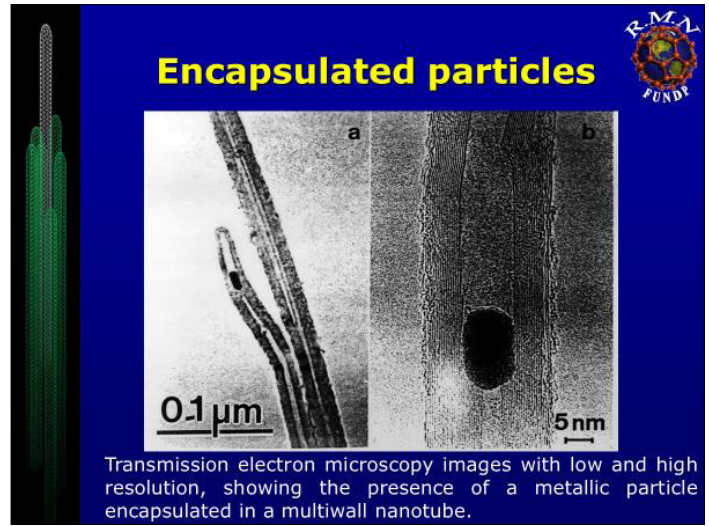

Figure 15. Encapsulated particles.

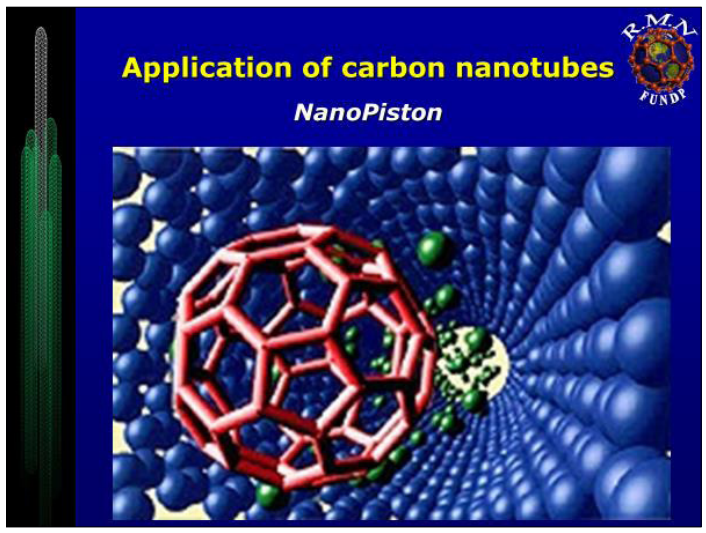

Figure 16. NanoPiston

The electron emitting properties can be used in vacuum lamps for lighting and in a flat - faced coloured screen (Figure 14.). Indeed, the first lamps used carbon fibres, but they had only a short life, that is why one replaced them by tungsten used until recently. Nowadays, one could come back to carbon, because the lifetime of carbon nanotubes is much longer.

Metal particles used as catalysts are sometimes encapsulated in the nanotube (Figure 15.). In addition, the figure shows that the end of the nanotube is closed. We have to open the nanotube by gentle oxidation and this way we can use them as sorbents. Hence, we can eliminate toxic gases, and for example, the carbon nanotubes adsorb dioxine 1,000 times better than the adsorbents known at present. In the open form, nanotubes are also used as sensors because their electric conductivity depends not only on the nature of the gases, but also on their quantity.

Carbon nanotubes can also be used as a Nanopiston. Figure 16. Illustrates the Nanopiston 


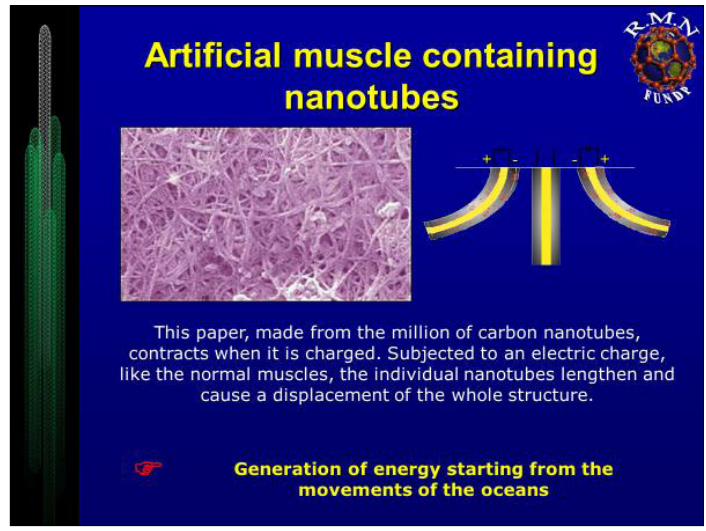

Figure 17. Artificial muscle containing carbon nanotubes.

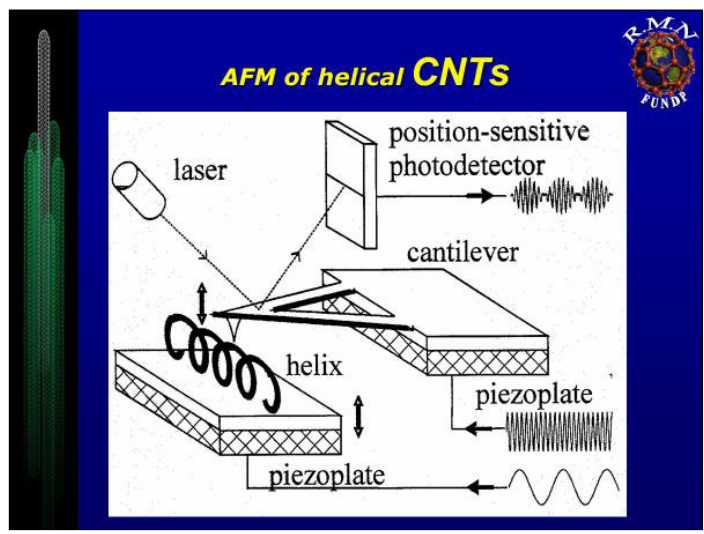

Figure 18. Atomic Force Microscopy of helical MWNTs.

functioning, where a fullerene molecule pushes the other molecules in the internal tube of a MWNT.

With the help of the carbon nanotubes, it is possible to realize an artificial muscle (Figure 17.).

Two sheets formed by carbon nanotubes are attached on an isolating plastic sheet. Into one sheet, a positive charge is introduced - hence the valence bond lengths are decreased - , while into the other, a negative charge is introduced - hence the valence bond lengths are increased. This provokes a bending imitating the movement of a muscle. Conversely, one could generate electricity by bending the sheet suspended in the sea. This experiment has already been realized near Lisbon in Portugal.

It is also possible to write on a silicon plate using carbon nanotubes, this is thus the NanoPencil [6].

We made the first NanoBalance using helical or coiled carbon nanotubes (Figures 18. and 19.).

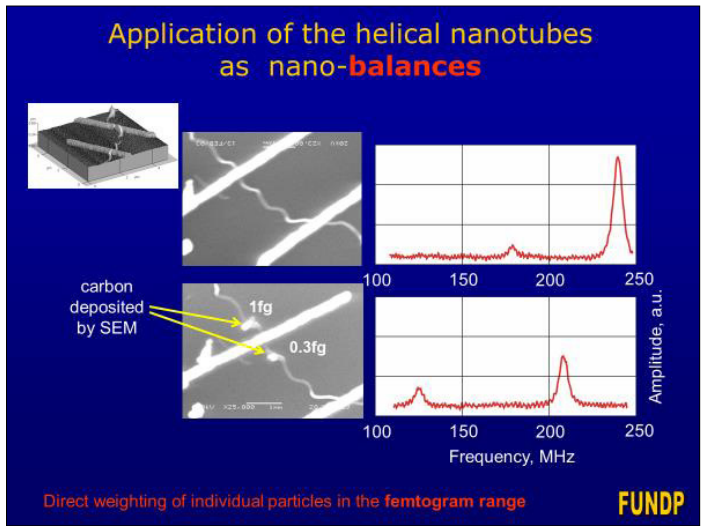

Figure 19. Use of helical carbon nanotube as a NanoBalance.

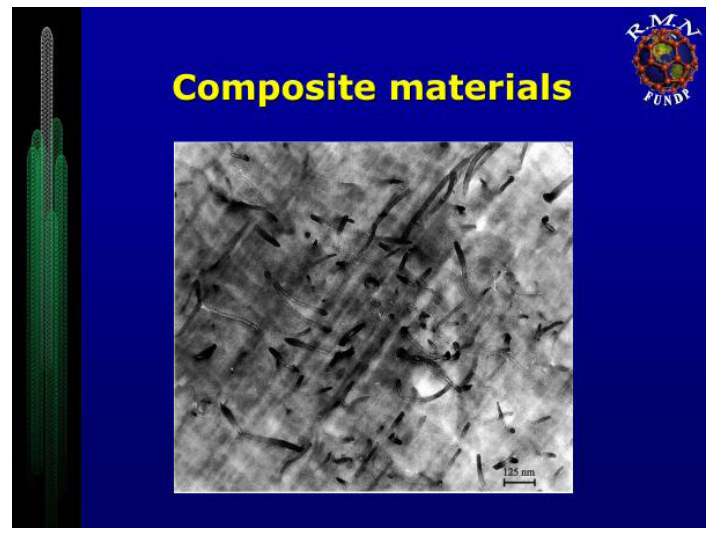

Figure 20. Dispersion in polymeric chains.

A coiled multiwalled carbon nanotube is deposited on the piezo plate of the Atomic Force Microscopy. With the tip of the cantilever one taps on the nanotube (Figure 18.). The basic frequencies in $\mathrm{MHz}$ are registered (Figure 19.).

When a nanoparticle is deposited on the coiled carbon nanotube, the basic frequencies are diminished due to the weight of the nanoparticle. From the differences in the frequencies it is possible to compute the weight of a single nano - particle: it is in the femtogram range $\left(10^{-15} \mathrm{~g}\right)$.

It is also possible to make a NanoSpring using coiled carbon nanotubes, by attaching one end to a fixed material [7]. One can measure the elastic modulus of the tube that is in the TPa range. Introducing current into a coiled nanotube, quite large magnetic fields can be induced leading to a NanoSolenoid [8].

The preparation of composite materials is very interesting. The dispersion of the nanotubes should be as good as possible in order to increase 


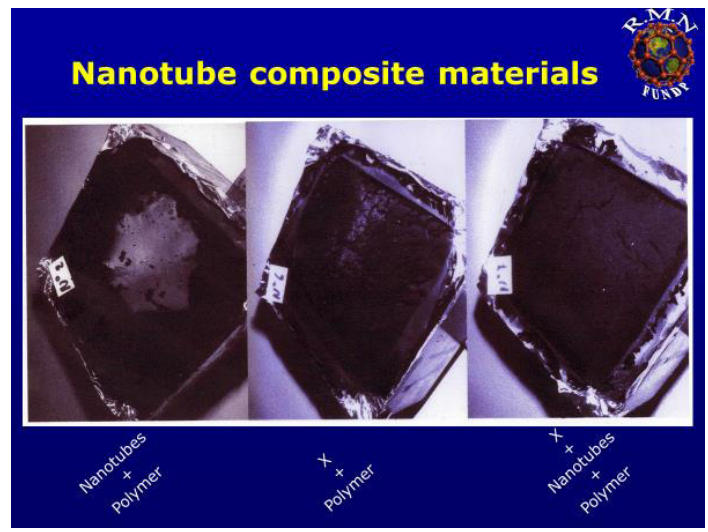

Figure 21. Flame retardant properties of composite materials.

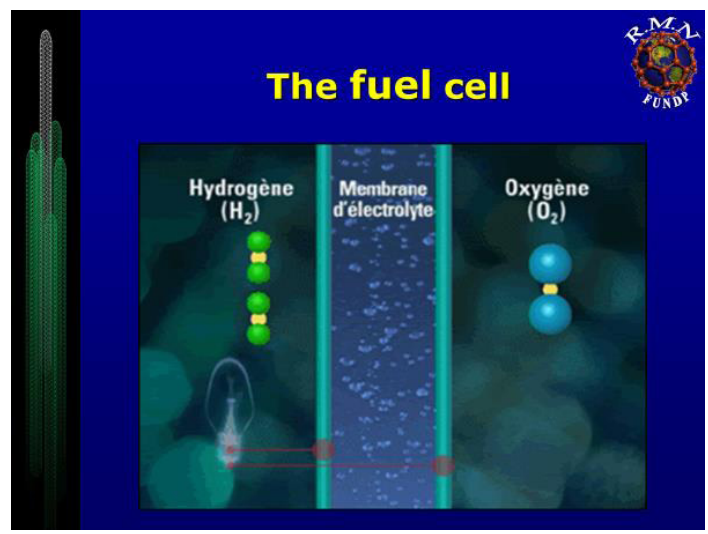

Figure 22. The fuel cell where the electrolyte membrane contains carbon nanotubes.

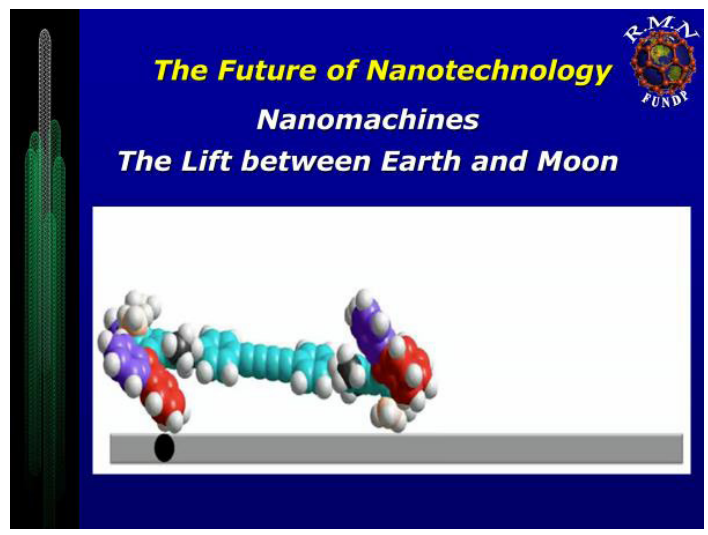

Figure 23. The future of nanotechnology. the interaction between the polymeric chains and the nanotubes (Figure 20.) [9].

The presence of nanotubes is also responsible for the flame - retardant properties of the composite material. The carbon nanotubes dispersed alone in the polymer have no flame - retardant properties (Figure 21. left picture). When some layered silicate is added to the polymer, the flame - retardant property is improved (Figure 21. middle picture). However, when both carbon nanotubes and layered silicate are dispersed, the result due to synergistic effects is excellent (Figure 21. right picture) [10].

Carbon nanotubes are also used in fuel cells where the membrane is composed of carbon nanotubes favouring the transfer of the hydrogen atoms towards the oxygen molecules that are reduced, thereby producing electric current (Figure 22.). These fuel cells are becoming increasingly important, because electric cars help to reduce $\mathrm{CO}_{2}$ content in the air.

Hydrogen can be directly produced by a heterogeneous catalytic reaction between water and methanol:

$$
\mathrm{H}_{2} \mathrm{O}+\mathrm{CH}_{3} \mathrm{OH}---3 \mathrm{H}_{2}+\mathrm{CO}_{2}
$$

The future of nanotechnology can be illustrated by the nanomachine formed by Prof. Jean - Pierre Sauvage, Nobel Prize in Chemistry in 2016 and the lift between Earth and Moon imagined by Rick Smalley, Nobel Prize in Chemistry in 1996 (Figure 23.).

The physics and chemistry of graphene (one single graphite sheet) are developing fast and are very promising. New sensors are found to detect the toxic gases. The use of carbon nanotubes in purifying waste waters is increasing in the scientific literature [11], as well as their use in preparing drinking water from sea water [12].

\section{Conclusions}

Nanoparticles were used in ancient times to prepare, for example, various coloured stained glass windows.

The endless applications of carbon nanotubes include nanoelectronics, nanosoleonids, nanosprings, nanobalances, flat - faced screens, composite materials, sensors, fuel cells...

The future of nanotechnology deals with nanomachines, graphene and its application, including water purification

\section{References}

[1] Baggott J.: Perfect symmetry. The accidental discovery of Buckminster-fullerene. Oxford University Press, 1996. 
[2] B. Nagy J., Bodart P., Hannus I., Kiricsi I.: Synthesis, characterization and use of zeolitic micro - porous materials. DecaGen Ltd., Szeged, Hungary, 1998.

[3] B. Nagy J., Barette D., Fonseca A., Jeunieau L., Monnoyer Ph., Piedigrosso P., Ravet-Bodart I., Verfaillie J.-P., Whatelet A.: Nanoparticles in microemulsions: a general approach. In: Nanoparticles in solids and solutions. (eds: Fendler J. H., Dékány I.) NATO ASI Series, 3. High Technology Vol. 18. Kluwer Academic Publishers, Dordrecht, 1996.

[4] In Building on fullerenes. Nature, 363. (1993) 6063.

[5] Amelinckx S., Zhang X.B., Bernaerts D., Zhang X. F., Ivanov V., B. Nagy J., Lucas A. A., Lambin Ph.: A formation mechanism of catalytically grown helix shaped graphite nanotubes. Science, 265/5172. (1994) 635-639. https://doi.org/ 10.1126/science.265.5172.635

[6] Dai H., Franklin N., Han J.: The high aspect - ratio nanopencil takes adventage of the small nanotube electrode size. Applied Physics Letters, 73. (1998) 1508-1510.

https://doi.org/10.1063/1.122188

[7] Bernaerts D., Zhang X. B., Zhang X. F., Amelincks S., Van Tendeloo G., Van Landuyt J., Ivanov V., B. Nagy J.: Electron microscope study of coiled carbon tubules. Philosophical Magazine A, 71. (1995) 605-630. https://doi.org/10.1080/01418619508244470
[8] Volodin A., Van Haesendonck C., Terbiainen R., Ahlskog M., Fonseca A., B. Nagy J.: AFM detection of mechanical resonances of coiled carbon nanotubes. Applied Physics, A72. [Suppl] (2001) S75S78.

https://doi.org/10.1007/s003390100644

[9] Coleman J. N., Cadek M., Blake R., Nicolosi V., Ryan K. P., Belton C., Fonseca A., B. Nagy J., Gun'ko Y. K., Blau W. J.: High-performance nanotube-reinforced plastics understanding the mechanism of strength increase. Advances in Functional Materials, 14/8. (2004) 791-798.

https://doi.org/10.1002/adfm.200305200

[10] Peeterbroeck S., Alexandre M., B. Nagy J., Pirlot C., Fonseca A., Moreau N., Destrée A., Philippin G., Delhalle J., Mekhalif Z., Sporken R., Beyer G., Dubois Ph.: Polymer - layered silicate - carbon nanotube nano-composites: unique nanofiller synergistic effect. Composites Science Technology, 64/15. (2004) 2317-2323.

https://doi.org/10.1016/j.compscitech.2004.01.020

[11] De Luca P., B. Nagy J.: Treatment of water contaminated with Reactive Black-5 Dye by carbon nanotubes. Materials, 13/23. (2020) 5508. https://doi.org/10.3390/ma13235508.

[12] Grosso V., Vuono D., Bahattab M. A., Di Profio G., Curcio E., Al-Jilil S.A., Alsubaie F., Alfife M., B. Nagy J., Drioli E., Fontananova E.: Polymeric and mixed matrix polyimid membranes. Separation Purification Technology, 132. (2014) 684-696. https://doi.org/10.1016/j.cossms.2004.09.003 